\title{
Filosofía de la biología en Iberoamérica
}

Philosophy of Biology in Iberoamerica

\author{
Mario Casanueva ${ }^{\dagger}$ \\ Carlos López Beltrán ${ }^{\ddagger}$ \\ Maximiliano Martinez
}

\section{Introducción}

La Asociación Iberoamericana de Filosofía de la Biología (AIFIBI) fue fundada al término de un congreso celebrado en Valencia (España), en noviembre de 2012, con el objetivo de dar cobijo y apoyo a actividades que contribuyan al desarrollo de la investigación, la docencia y la comunicación pública de la Filosofía de la Biología y de las disciplinas afines en el ámbito cultural iberoamericano. Los estudios sociales, históricos y culturales de las ciencias de la vida se incluyen como parte del espacio relevante para la actividad de esta asociación. En esta asociación han confluido investigadores y grupos que previamente habían estado desarrollando trabajos importantes y redes en diferentes polos de Iberoamérica. En Brasil, Colombia, México, España y Argentina de manera más notable. Esfuerzos previos de vinculación y articulación comunitaria, como el del grupo Bogotá, o articulado en torno a la revista Ludus Vitalis, por mencionar sólo dos (sin demérito de otros) vieron fructificar sus trabajos con la consolidación de AIFIBI.

A fin de cumplir sus objetivos, AIFIBI organiza, entre otras acciones, un congreso de dimensión Iberoamericana cada tres años. El volumen que ahora prologamos incluye una selección representativa de los trabajos presentados durante el segundo congreso de AIFIBI, celebrado en septiembre de 2015 en Valle de Bravo, México. Las líneas que siguen se ofrecen como un marco histórico-conceptual en el que se ubiquen las diferentes contribuciones que aquí convergen.

\section{Filosofía de la biología y biología un largo camino}

La filosofía ha acompañado a las ciencias biológicas en su marcha hacia la autonomía disciplinar y explicativa, juntas atravesaron los espacios de la entelequia, de la distinción acto-potencia y de la interrelación de los cuatro tipos de causas; juntas caminaron bajo los coros del mecanicismo, que negó la autonomía de la biología; juntas transitaron el imaginario vitalista organicista, en donde se amalgamaba lo relacionado con la vida con todo lo demás. La autonomía disciplinar fue conquistada una vez que se hizo claro, en la época moderna, que a pesar de que la física y sus leyes no eran violadas por la vida, la comprensión cabal de los fenómenos vivos exigía ampliar tácticamente la metodología y la epistemología de las ciencias (y cuidar que esto no obligase a ampliar la ontología en concesión al vitalismo o al finalismo) para poder articular los saberes biológicos.

Los filósofos han buscado la articulación entre lo inerte y lo vivo, sobre goznes: estructurales (forma, orden, organización y relación partes y todo), funcionales (disposiciones o eficacias causales más o menos específicas que parecen canalizadas hacia fines, ya sea internos del organismo o externos desde el organismo hacia su entorno) e históricos (procesos contingentes desplegados en tiempo de

\footnotetext{
† Departamento de Humanidades, Phibio, REMO, Universidad Autónoma Metropolitana-Cuajimalpa. Para contactar al autor, por favor, escribir a: mario.casanueva@gmail.com.

* Instituto de Investigaciones Filosóficas, Universidad Nacional Autónoma de México/Phibio. Para contactar al autor, por favor, escribir a: carloslopezbeltran@gmail.com.

$\S$ Departamento de Humanidades, Phibio, Universidad Autónoma Metropolitana-Cuajimalpa. Para contactar al autor, por favor, escribir a: mmartinez@correo.cua.uam.mx.

Metatheoria 8(1)(2017): 1-10. ISSN 1853-2322.

(C) Editorial de la Universidad Nacional de Tres de Febrero. Publicado en la República Argentina.
} 
adquisición de orden, complejidad). La compañía de la filosofía, en forma de crítica metafísica, epistemológica, psicológica, sociológica e histórica, ha contribuido por un lado a robustecer la voluntad de construir y evaluar los saberes biológicos a partir de sus propios raseros y, por otro, ha ayudado a definir los alcances y límites de los entusiastas despegues teóricos de sucesivas épocas. Protegerla de los imperialismos reduccionistas de ciencias más añosas y "fundamentales" y limitar a su vez sus proclividades imperiales frente a las ciencias humanas y sociales.

Las generaciones coevas y posteriores a Descartes (los modernos) desacoplaron la trama de los efectos holistas que organizaba (sincronizaba, sintonizaba, modulaba) el mundo según los antiguos. Con Aristóteles, las plantas y animales poseen almas que los tornan complejos y diferentes en su estudio. También Descartes distinguió entre seres inertes y animados pero, contra la tradición, negó un alma a plantas y animales. Sin ella sus voces, signos y modos, son hermanos de los golpeteos, chirridos y desplantes de un artefacto articulado. Sólo los humanos sienten, sólo los humanos piensan. La Naturaleza toda, se moldea en factorías y se ciñe a los cánones de la mecánica. La única causa es la interacción eficiente, el contacto físico entre cuerpos en movimiento. Así, lo vivo queda exento de autonomía o peculiaridad. La nueva exigencia de claridad y especificidad en los vínculos y nexos causales (contacto, empuje, eficacia) y la preeminencia de la intuición mecánica sobre las intuiciones de propósito, o de armonía y pre ordenamiento, allanaron el camino para la simplificación de la comprensión (la modelización) de las dependencias causales de la física, pero generaron paradojas y pasmos respecto a la química y a los procesos/fenómenos vitales. El hiato entre materia inerte y materia animada se volvió obvio.

Desde Lucrecio y los atomistas (materialistas) se tenía muy claro que las trayectorias de los sistemas causales del caos al orden, de la confusión a la organización, de la indiferenciación a la complejidad (para usar lenguaje extremadamente anacrónico) constituía un serio problema para el minimalismo ontológico y causal. La necesidad de postular un conductor, un cauce, una guía (en el sentido de riel o de detonador) para el desequilibrio que pudiese dar lugar a la diferencia, a la multiplicidad, de entes coordinados y articulados en cadenas y en ciclos recurrentes, llevó a Lucrecio a imaginar el clinamen; esa intervención misteriosa que causa condensaciones y vórtices. Siglos después, ya en el ámbito mecanicista, Boyle (más consciente que Descartes de las dificultades químicas y fisiológicas de los modos simplistas de ascender en el ordenamiento de causas desde lo inerte hasta lo vivo) mencionó la existencia y eficacia de ciertos "contrivances" o constricciones de las formas materiales presentes (sembradas) en la organización más simple de lo vivo, capaces de canalizar las secuencias causales para contener los procesos dentro del rango de lo vivo (y no se desordenaran) y de originar los ciclos y despliegues embriológicos de cada nuevo ser. La forma como contenedor de la función. La forma sin historia. Estas constricciones son similares en rol a las predisposiciones que imaginaron los prefomacionistas y epigenestistas ilustrados, y que retoman filósofos para alegar la inevitabilidad de la comprensión teleológica, son también el nodo de la aparente inexplicabilidad mecánica (reduccionista, o histórico material). Particularmente Kant, consideró que la complejidad de lo viviente, su reproducción, su desarrollo y su regeneración, le hablaban más bien de organización. Los organismos están constituidos con arreglo a determinados fines, manifiestan un plan, un diseño, sus partes están estructuradas en función de su mutua complementariedad y son inteligibles sólo en su interacción con las otras y con el despliegue de funciones que desarrolla dentro de una globalidad a la que se le considera un fin en sí misma, un propósito de la Naturaleza. Para el filósofo de Königsberg, la mecánica no puede dar cuenta de, por ejemplo, la organización, desarrollo, o reproducción de los seres vivos, es menester postular principios adicionales de propositividad, causas o disposiciones finalistas para los rasgos o propiedades de lo biológico. Kant, los asume, casi con pesar, de manera subjetiva, como herramientas heurísticas para la inteligibilidad. El juicio con ellos obtenido no conduce, como en la física, a un conocimiento cierto, a un juicio determinante, sino a uno reflexivo. Schelling, Goethe y el resto de la Naturphilosophie, concordaron con Kant en postular la propositividad; oponiéndosele, la consideraron -no un elemento subjetivo sino- un principio ontológico, rector del mundo orgánico, de la biología y de su filosofía que al mismo tiempo otorga preeminencia a la historia. En la medida en que la propositividad, o si se prefiere, el carácter con arreglo a fines, está vinculado con la 
reproducción, el desarrollo y la regeneración, el organismo, produciéndose a sí mismo, se torna causa y efecto de su autorrealización. Los seres vivos devienen constantemente y es por ello que conforman entidades con una historia propia.

El funcionamiento sincronizado de las partes de un organismo puede explicarse parcialmente por la forma, por el orden general de las estructuras y por sus dependencias holistas. Y también parcialmente por la acción acumulada de las capacidades causales de cada elemento o parte del todo. La teleología externa debe, al menos desde Lamarck y Cuvier, cargarse más hacia la articulación (modulación) histórica de la interacción entre los rasgos y disposiciones causales de los organismos y las condiciones materiales de su entorno (las "condiciones de vida"). Esta historicidad fue la contribución del siglo XIX sobre la que Darwin logró finalmente unir en un solo territorio epistemológico los aspectos antes disociados de la estructura (forma) y la función (adaptación). Aunque el territorio siguió presentando regiones opacas o indóciles a la elucidación analítica, el hiato originario se cerró en gran medida. La filosofía de la biología aún hoy puede describirse como centrada en problemas o aspectos estructurales, funcionales o históricos de la vida, y de las teorías, en sus dimensiones ontológica, epistemológica y metodológica. Durante el periodo clásico del siglo XX, ella se articula básicamente en tres problemas principales:

(i) La naturaleza y peculiaridades del conocimiento biológico. Como en épocas pasadas, la autonomía disciplinar contendió contra la derivación o reducción respecto a disciplinas más "básicas", en las arenas de la lógica, la ontología la epistemología y la metodología Descartes defendió la reducción en los terrenos de la ontología y, por extensión, en el resto de espacios conceptuales hacia la epistemología y la metodología. Hoy aún subsisten los excesos en favor del gene-centrismo epistemometodológico o de sus contrapartes composicionalistas (enfocar sólo el nivel de los organismos, las poblaciones o las comunidades) pero, con fines heurísticos, se consienten ambos.

En el terreno epistemológico, cuestiones que antes se discutían en términos de reduccionismo entre leyes o teorías, en favor de disciplinas o niveles más fundamentales (p.ej. la reducción de la genética clásica a la molecular), han dejado paso a interrogantes acerca de la objetividad, independencia e interdependencia de y entre los diferentes niveles de la jerarquía de organización biológica, el emergentismo de propiedades biológicas, el de la acción de mecanismos o la búsqueda de nuevas metáforas para pensar la biología (y aunque en determinados contextos todavía se siga hablando de leyes, ya no se consideran como universales irrestrictos y se postulan diferentes tipos y niveles de contingencia para las mismas). Las formas en las que la organización compleja de los seres vivos puede originarse y mantenerse dentro de sistemas integrados dedicados a la satisfacción de sus propias metas, ha dado lugar al nacimiento de temas como la autonomía biológica o, incluso, disciplinas como la biología artificial y la biología teórica más o menos especulativa.

(ii) Los debates en torno a la naturaleza de la teoría de la evolución darwiniana y, en particular, el principio de selección natural, constituyen una polémica viva. Más ahora, la expresión "revolución darwiniana" desdibuja su señalamiento como lugar común. Por una parte, la idea misma de revolución científica está en tela de juicio y, por la otra, la mayor o menor importancia del mecanismo (o del proceso) de selección natural en la evolución de los seres orgánicos es tema de continuo debate. Sin embargo, la preeminencia que tienen el pensamiento darwiniano y sobre todo la productividad epistémica de la Selección Natural, tanto en la historia intelectual de occidente como dentro de la biología, sólo es puesta en duda casuística y marginalmente. Atrás han quedado las deliberaciones sobre los pretendidos vicios de vacuidad empírica o circularidad conceptual de la selección natural. Su lugar en la agenda lo ocupan temas como el preciso significado del concepto de adecuación o aptitud (fitness). ¿Se trata o no de una fuerza o de una propensión?, o ¿cuál es la relación entre las distintas expresiones matemáticas que pretenden recuperarla (tanto entre sí como con las técnicas para su determinación)?, ¿cuáles son las formas de la multirrealizabilidad del concepto de selección natural?, o ¿cuál la importancia relativa de la selección respecto a otros mecanismos (o procesos) de cambio evolutivo?, ¿cómo surge la posibilidad de la auto-organización o generación de la complejidad biológica, en ciclos de vida cortos o en la sucesión histórica, a partir de estructuras simples? Surgen nuevas maneras de interrogar sobre la naturaleza epistémica y el alcance de los principios darwinianos: el 
cambio que proponen quienes defienden la Síntesis evolutiva extendida, caso de ser aceptado, ¿es lo suficientemente relevante como para ser considerado una propuesta radicalmente distinta o puede ser asimilado a una serie de otros cambios que se han dado ya?

(iii) La naturaleza de las explicaciones funcionales. Desde Aristóteles, el establecimiento de explicaciones que apelan a causas teleológicas o disposiciones finalistas ha sido considerado una nota distintiva del conocimiento de plantas y animales (y demás seres orgánicos, si Aristóteles les hubiese conocido). Para el estagirita la causa final prima sobre las demás, pues una vez que ha sido determinada, las otras (material, formal y eficiente) deben ajustarse a ella. La pérdida del telos causal holístico trajo consigo la necesidad de entender y justificar de otro modo la finalidad real (o aparente) de los organismos, que en ciertos campos como el estudio de los procesos del desarrollo parecen ser irreductibles. Una estrategia reciente fue el asimilarlas a un paradigma seleccionista. Enunciados del tipo "las aves tienen plumas y alas para volar" no serían sino una forma abreviada de señalar que la selección natural ha favorecido a aquellos ancestros de las aves que desarrollaron determinadas conductas como el batir de los brazos en la carrera, al tiempo que saltaban. En la medida en que las incipientes plumas de las alas (quizá originalmente desarrolladas para otro propósito como termoregulación) permitían saltos ligeramente más largos, caracteres y conductas evolucionaron hasta conformar las estructuras y comportamientos actuales. Bajo esta ruta de pensamiento, las alas en las aves cumplen una función teleológica, i.e., sirven al vuelo, pero su diseño no se considera producto de la ejecución de un plan preexistente. El problema ahora radica en que la confluencia de varias cadenas causales debe ser puesta en sintonía no sólo entre sí, también con las ventajas selectivas operantes en un determinado momento.

Como la biología misma, la filosofía de la biología ha sufrido un crecimiento exponencial en su importancia como disciplina académica a partir de la mitad del siglo XX. De ser una subdisciplina menor dentro de la filosofía de la ciencia dominada por la física, ha pasado a ocupar un lugar de privilegio no sólo por la centralidad de sus problemas teóricos y filosóficos, sino también por las múltiples conexiones y ramificaciones que ha establecido con problemas muy diversos y dispersos de otras disciplinas y de dominios centrales para la tecnociencia, la política y la ética contemporáneas. Se ha puesto a la vida misma en el centro de muchas de sus paradojas, disputas y conflictos. Con las crecientes capacidades tecnológicas de los saberes biomédicos, bioantropológicos y biopolíticos, la filosofía ha tenido que acompañar a las ciencias de la vida en territorios cada vez más complejos y urgentes, que se imbrican no sólo en cómo debemos vivir, sino en la posibilidad misma de que la vida como la conocemos continúe. Las capacidades de transformación de la vida y de los espacios vitales de las biotecnologías a partir de mediados del siglo XX han generado muchas alertas y debates bioéticos y biopolíticos que además han debido ser situados y regionalizados. La comprensión teórica de lo viviente, desde la filosofía, se ha vuelto central para la filosofía de la mente, para la bioética, para las filosofías ambientalistas o animalistas, para las tecnologías de la reproducción, para las tecnologías del mejoramiento humano, animal, vegetal, para la comprensión del funcionamiento explicativo de muchas disciplinas, ciencias cognitivas y psicología, sociología y epistemología evolucionista.

Lejos estamos, en esta segunda década del siglo XXI, de los tiempos en los que el funcionamiento explicativo de la teoría darwiniana y las capacidades de resistir los imperialismos reduccionistas de la química, la física o de los holismos vitalistas, o la indispensabilidad del agregado teleológico, eran vistos como los problemas únicos y centrales de filosofía de la biología. Hoy siguen con nosotros esos temas pero acompañados de una gama amplísima de extensiones vinculadas a espacios y prácticas muy diversas. Las fronteras que la biología y las biotecnologías han desarrollado con muchas otras disciplinas y prácticas científicas, técnicas y políticas, han producido una enorme e intensa actividad interdisciplinaria en la que la biología ha debido arremangarse la camisa y ponerse a construir espacios de representación, intervención y solución de problemas de modos diversos y dispersos. Aunque por un lado su autonomía e identidad disciplinar pueda, para ciertos nostálgicos, estar siendo amenazada, la realidad es que se ha convertido en una disciplina mucho más sólida, valiosa y útil. Y filosóficamente mucho más rica, compleja e interesante. 


\section{Algunas fronteras (activas, fluidas) dentro de AIFIBI}

Cada nueva frontera de la biología ha construido sus propios debates y sus propios espacios para la articulación filosófica. Lo que proponemos al lector son un conjunto de secciones que agrupan textos dentro de tales fronteras. La primera sección, de corte más bien clásico y titulada "Influencia de Darwin y debates neodarwinistas" está dedicada a las reflexiones en torno a la clarificación conceptual, la estructura, los alcances, los efectos, y las polémicas en torno al pensamiento evolucionista. El texto inicial de Maximiliano Martínez pasa revista a las improntas que la obra de Darwin ha dejado sobre diversos territorios filosóficos. Su lista abarca la teología, la metafísica, la epistemología, la filosofía de la ciencia, la filosofía de la mente y la ética. En todos estos espacios el darwinismo o bien contribuyó a socavar algunos argumentos clásicos, o bien sentó las bases para la apertura de nuevos horizontes y estilos argumentativos a los que se dio carta de pertinencia y legitimidad. Martínez muestra, por ejemplo, como nuestras creencias sobre los juicios morales no son ajenas a reflexiones acerca de los orígenes del altruismo, la cooperación o el valor adaptativo de grupos que pueden realizar tales juicios. Con independencia de la opinión que nos merezcan estas expansiones territoriales darwinistas, constituyen una moneda de cambio legítima que no puede ser soslayada en el panorama de la filosofía contemporánea.

Cualquier trabajo académico en torno a la teoría de la evolución darwiniana, que se pretenda mínimamente completo, debe considerar la ya larga serie de intentos que intentan aclarar su estructura conceptual, en particular la de la selección natural. La discusión se retrotrae a Darwin, quien la consideró análoga a otras leyes de la Naturaleza como la ley de la gravitación. Por el contrario, Elliot Sober ha sostenido que a diferencia de lo que ocurre en la física y en concreto en la mecánica clásica, la selección natural contempla modelos explicativos/condicionales que pueden ser tipificados como siendo a priori. José Díez y Pablo Lorenzano, usando ideas y métodos propios de la concepción estructuralista de las teorías empíricas, confrontan en su trabajo a Sober, al argumentar en favor de la idea de que los modelos explicativos/condicionales específicos en la selección natural no difieren en su naturaleza de los de la mecánica clásica; y si aquéllos debieran ser considerados a priori, también debieran serlo éstos. Además, sostienen que los postulados fundamentales (a los que llaman "principios-guía") de las teorías científicas, sean éstas físicas, como la mecánica clásica, o biológicas, como la slección natural, son, entre otras cosas, empíricamente irrestrictos (por sí solos no contravienen ninguna situación de estados del mundo). Según esta consideración, el principio de selección natural (de manera análoga a lo que ocurre con la segunda ley de Newton) va cargándose de contenido mediante una serie de sucesivas especificaciones adicionales que dan lugar a diversas especializaciones teóricas a las que el principio abarca a manera de un racimo o red teórica.

Las redes teóricas como las que presentan Díez y Lorenzano establecen un ordenamiento metódico de las diferentes aplicaciones de las teorías, más también otras tipologías menos sistemáticas son pertinentes. El texto de Santiago Ginnobili y Ariel Roffé analiza las relaciones entre los modelos de optimalidad y dos tipos de presentaciones de la idea de selección natural. Uno de tales tipos, las presentaciones "históricas", contempla el proceso evolutivo como una serie de episodios, una sucesión de estados de una población a lo largo de las generaciones. Una cadena de transformaciones coherentes (de acuerdo con los principios postulados por la selección natural) da cuenta de la adaptación de los organismos al ambiente. Por su parte, en las presentaciones "ahistóricas", lo que se explica es el éxito reproductivo diferencial de diferentes clases (heredables) de organismos (su tasa de cambio) en un determinado ambiente y tiempo; las consecuencias de mantener esta tasa reproductiva diferencial a lo largo del cambio transgeneracional se consideran una inferencia posterior. Entre otros, el análisis de Ginnobili y Roffé muestra la relación entre ambos tipos de explicaciones: las históricas contienen una iteración de las ahistóricas.

Según una conocida interpretación de Gould, Darwin nos proporcionó tres maneras de inferir la historia a partir del presente, sumar pequeños efectos a lo largo de grandes intervalos (como la formación del suelo por la acción de las lombrices) aprender a ver los diferentes casos como dispuestos a lo largo de una serie (como en su idea sobre la formación de los atolones, que los considera una etapa 
de la formación de islas coralinas) o mirar las imperfecciones y semejanzas de diseño como huellas de un origen. Saber ver en las especies actuales su historia evolutiva, leer en ellas las bifurcaciones del caudal de la vida, implica, en buena medida, diferenciar analogías y homologías. El trabajo de Claudia Lorena García hace un análisis pormenorizado de tres conceptos fundamentales usados en la morfología comparada: paralelismo, convergencia y homología profunda. La discusión acerca de su definición, relación e incluso utilidad es permamente en la literatura, por lo que García propone una reformulación (empíricamente consistente, como señala la autora) de dichas nociones que permite relacionarlas con dos teorías de la estabilidad y cambio ontogenético, como lo son el modelo del desarrollo como un "embudo" y el modelo del desarrollo como un "reloj de arena". Centrales en la propuesta de García resultan el concepto de causalidad intervecionista de Woodward y la noción de causa específica.

Cierra esta sección el texto "De la selección natural al diseño: una propuesta de extensión del darwinismo formal” de Giorgio Airoldi y Cristian Saborido. Como señalan Ginnobili y Roffé, en la literatura biológica los argumentos de optimización de la eficacia que apelan a la selección natural son cotidianos. Sin embargo, hoy día, tales argumentos carecen de una presentación formal precisa que goce de aceptación general. Airoldi y Saborido pretenden solventar este problema. Su estrategia consiste en partir de la propuesta del darwinismo formal de Alan Grafen y mejorarla con base en formulaciones más realistas que al mismo tiempo den cuenta de una serie de críticas ya conocidas (la selección natural no es el único factor evolutivo, el concepto de fitness es polisémico, la fitness debe diferenciarse del diseño). En su aspecto propositivo destaca la idea de representar los estados fenotípicos como constreñidos en un espacio bidimensional que considera eficiencia versus robustez. De manera similar a como ocurre en los contextos de los espacios de estados, las leyes de la evolución determinarían las trayectorias de movimiento dentro de ese espacio, siendo la selección la principal responsable del componente a lo largo del eje de la eficiencia y los mecanismos no selectivos darían cuenta de los movimientos a lo largo del eje de la robustez. Con independencia de lo acertado o no de la propuesta, es significativo que la misma contemple otros vectores evolutivos distintos a la selección natural. En este sentido cabe considerarla como una tesis que abona a la construcción de lo que se ha llamado síntesis evolutiva extendida.

La segunda sección, titulada "Modelos y representación en la biología: miradas desde la epistemología" incluye cuatro reflexiones epistemológicas que implican de diferentes maneras la idea de modelo y de representación. En "Diagramas y esquemas en y sobre la genética mendeliana", Mario Casanueva, tiene una doble intención, por un lado, en el contexto del caso, considera a las teorías como familias de modelos y representa a los modelos mediante recursos gráfico-matemáticos. Por el otro, usa tal(es) grafo(s) para dar cuenta de la centralidad de un determinado tipo de esquema o tabla de cálculo ampliamente extendida en genética mendeliana, el cuadro de Punnett. Los grafos son tanto representación de los modelos como herramienta epistémica para el estudio para otros tipos de representaciones y modelos.

Una pregunta ampliamente extendida en torno a la naturaleza de los modelos, es ¿qué tanto se aproximan a la realidad? o ¿en qué grado pueden representarla, aunque sea con falsedad? En "Modelos falsos en la ciencia: un valioso recurso para la comprensión de los fenómenos", Antonio Diéguez aborda la pregunta “¿cómo tiene lugar la comprensión mediante modelos falsos?". Para elucidarla establece (sin compromiso de exhaustividad) una tipología basada en usos que reconoce cuatro clases de modelos: los "ajustables", susceptibles de ampliaciones o correcciones que les van dotando de mayores compromisos ontológicos; los "plantilla", que postulan una situación ideal, empíricamente imposible, de la que se desvían en mayor o menor grado; los "no denotativos", que "postulan entidades, propiedades o mecanismos carentes por completo de referencia" (i.e., refieren a cosas que no hay). Finalmente, los "contrastantes", a los que podríamos denominar "modelos por reducción al absurdo", nos muestran las consecuencias poco realistas que tendría suponer la existencia de determinados estados de cosas. Diéguez cita a Weisberg al respecto: "en la medida en que podemos entender porqué no existen [los fenómenos descritos por el modelo], podemos haber obtenido una mejor comprensión de los fenómenos que sí existen”. Hacia el final de su texto, Diéguez sigue a 
Morrison: "Dado que muchos modelos no pueden ser evaluados sobre la base de su capacidad para proporcionar una representación realista, necesitamos centrar menos nuestra atención en la distinción entre modelos 'heurísticos' y modelos 'realistas', y en lugar de eso, hemos de subrayar el modo en que los modelos funcionan en el desarrollo de leyes y teorías".

El texto de Diéguez llama la atención al señalar la posibilidad de comprensión mediante modelos falsos, mientras que el de Alfonso Arroyo-Santos trae a nuestra mesa conceptos que no poseen un único referente sino una multiplicidad, en la que el uso correcto o la adecuada determinación del concepto apela a reglas y procedimientos que no son necesariamente coherentes entre sí. El autor usa al concepto "radiación adaptativa" como ilustración de la forma en cómo una tipificación conceptual operativa da cobijo a varias formas de organización de los resultados de la investigación empírica (e.e., múltiples modelos de datos), a los que Arroyo-Santos denomina múltiples objetos epistémicos, que a su vez se relacionan con el mundo (lo representan-construyen) de diversas maneras. Para Arroyo-Santos "el análisis muestra que la operativización no necesariamente converge hacia un concepto consistente"; más bien, se trata de "grandes intuiciones" que "puede(n) ser investigada(s) de muchas maneras".

Aunque de distinta manera, la idea de que la ciencia contiene grandes intuiciones multirrealizables también se hace presente en el trabajo de Lucía Federico. Su texto: "El puzle de las teorías de las proteínas funcionales: ¿qué tiene en común el ibuprofeno con el envenenamiento por monóxido de carbono? Una respuesta filosófica a un problema científico", asume las tesis de la concepción estructuralista de las teorías empíricas, en particular la idea de que las teorías constan de familias de modelos agrupadas según un orden arbóreo de líneas de especialización. El rompecabezas que enfrenta Federico la conduce a la búsqueda de una pieza faltante, se da a la caza de una teoría implícita no reportada en la literatura. El artículo muestra que: (i) en la literatura científica los fenómenos/mecanismos bioquímicos asociados al poder curativo del ibuprofeno y al poder tóxico del monóxido de carbono tienen lo suficiente en común como para que sus respectivas explicaciones se consideren parte de una misma teoría en sentido amplio; (ii) dichas explicaciones no pueden ser reconstruidas como pertenecientes a una misma teoría atendiendo a la reconstrucción de dos candidatos naturales: la cinética michaeliana (que reconstruye la autora) y la teoría alostérica (ya reconstruida en la literatura). En consecuencia, se hipotetiza una teoría más general/unificadora /omniabarcante de acuerdo con la cual dichas explicaciones correspondan a especializaciones (en sentido estructuralista) de esa teoría más general.

La sección tres, titulada "Fronteras en la epistemología de la biología", inicia con un trabajo de Gustavo Caponi titulado "Sobreestimación epistemológica de la construcción de nicho", en donde se cuestiona el papel independiente (y en no pocos casos, preponderante) que muchos autores le otorgan a la construcción de nicho como factor evolutivo por encima de la selección natural. Sin restarle importancia a tales ideas, Caponi defiende que la construcción de nicho de hecho se subsume bajo la selección natural, resultando más bien análoga a la lucha por la existencia como estatuto explicativo. De esta forma, para el autor, los teóricos de la construcción de nicho caen en una suerte de error categorial, al considerar que ella trabaja en conjunción y paridad causal con la selección natural, cuando resulta ser un factor subalterno a aquélla. A continuación, desde la otra orilla, Eugenio Andrade argumenta en su texto a favor de una idea que ha venido defendiendo desde hace ya varios años: la teoría de los sistemas en desarrollo resulta el espacio idóneo para disolver la dicotomía internalismo-externalismo en la biología evolutiva, allanando el camino para una teoría extendida de la evolución que no se centre en el poder creativo de la selección natural. El punto central defendido por Andrade es que factores como la auto-organización y la epigénesis son condiciones biológicas previas a la operación de la selección natural, principalmente por su capacidad en la generación de novedades no aleatorias sobre las que opera posteriormente el factor darwiniano. Andrade sustenta su postura en la noción de 'especies como individuos'. Cerrando la sección tres encontramos el trabajo "iQué significa hoy la idea de autonomía para la Biología?", escrito por Alvaro Moreno, texto que coincide con el anterior en resaltar la importancia de los factores internos y de auto-organización de los organismos, pero cuyo concepto central es la autonomía. Moreno llama la atención sobre la necesidad e importancia de revisar la idea de autonomía en la evolución y comprenderla como un concepto aún 
más fundamental que el de selección natural, puesto que aquél captura características esenciales y primarias de los organismos tales como auto-organización, auto-producción y auto-mantenimiento que se escapan no sólo al factor darwiniano, sino también a la forma en que la autonomía se ha entendido usualmente, esto es, en términos de autosuficiencia.

El estudio de los procesos cognitivos, la filosofía de la mente y la psicología y las neurociencias no han escapado al enorme influjo de la teoría de la evolución. La cuarta sección del volumen, titulada "Neurociencia, mente y cognición", recoge cuatro trabajos que dan muestra de ello. El primer texto, preparado por Sergio F. Martínez y Luis A. Villanueva Hernández, defiende que una perspectiva de la mente extendida (situada, corporizada, encarnada), que ve a la cognición como una interacción indisoluble entre organismo y entorno, permite considerar a las prácticas musicales como parte de las tecnologías cognitivas básicas que a su vez resultan ser andamios (de formación y mantenimiento) para el desarrollo de la cognición social. Esta relación debe llevar, argumentan Martínez y Villanueva, a una nueva manera de abordar los estudios musicales. A continuación encontramos el trabajo de Vicente Claramonte, titulado "Las neuronas espejo, presupuesto fisiológico de la empatía emocional y de las conductas sociales y morales en primates humanos y no humanos". El autor abunda sobre un tema que ha estado en discusión desde hace varios años: la relación de las neuronas espejo con la emoción de la empatía intersubjetiva, fundamental para el comportamiento social y cooperativo, a su vez central para comprender las bases de la moralidad. Claramonte defiende que la investigación experimental reafirma este vínculo y responde algunas objeciones hechas a esta última. Paola Hernández Chávez, autora del siguiente artículo, retoma la vía crítica de la tesis de la modularidad masiva de lo mental. Basándose en evidencia experimental, antropológica e histórica acerca del desarrollo de dos de nuestras capacidades cognitivas básicas, la conceptualización del tiempo y la matematización, Hernández defiende que éstas no pueden explicarse como capacidades innatas evolutivas modulares puesto que son de adquisición tardía mediante aprendizaje y de naturaleza relacional y compleja. Esto debe llevar a reconsiderar la tesis de la modularidad masiva, argumenta la autora. La sección cuatro finaliza con el artículo conjunto de Jonatan García Campos, Paola Hernández Chávez, Maximiliano Martínez y Roberto Soto López, quienes retoman el debate tradicional acerca de la tesis de la múltiple realizabilidad y de las clases naturales en biología. Los autores argumentan que desde las neurociencias no es posible descartar la tesis de la múltiple realizabilidad, para lo cual cuestionan cuatro de sus supuestos básicos: las comparaciones entre especies, la supuesta continuidad de mecanismos entre éstas, la unicidad de sus funciones cerebrales y la existencia de un sustrato neuronal común.

La sección cinco, cuyo título es "Intersecciones y acoplamientos entre biología y técnica", agrupa dos trabajos. El primero, escrito por Jaime Fisher, descansa en un supuesto indiscutible para el autor: el continuo entre biología y cultura. Este supuesto le permite relacionar la filosofía de la biología y la filosofía de la técnica desde una perspectiva inversa a la usual (y más interdisciplinaria), esto es, considerando de forma central "las bases técnicas de la evolución biológica". Así, es posible estudiar, desde una heurística muy provechosa, las bases biológicas de la conducta técnica, a la vez que las bases técnicas de la conducta biológica.

Esta sección cierra con el artículo de Guillermo Folguera y Nahuel Pallitto, quienes discuten la propuesta de Moss acerca de la independencia actual de dos nociones de gen: la clásica de poblaciones y la molecular. Para los autores, tras un estudio de diversos trabajos en el área de la genética, dicha independencia conceptual es inexistente, toda vez que la noción usual es una de carácter híbrido entre la clásica y la molecular. Más aún, los autores señalan que esto es muestra de una tendencia reduccionista, opuesta a un pretendido pluralismo en la investigación en el área.

La sección seis nos introduce en un espacio más amplio y polifacético en el que las ciencias biológicas contemporáneas, diversificadas en prácticas disciplinares varias, y volcadas sobre trincheras de actividad biopolítica complejas, piden del filósofo y del analista otras habilidades y recursos. Bajo el rubro de "Biología y heurísticas para la interdisciplina", agrupamos cinco trabajos que apuntan, cada uno en su nicho de complejidad disciplinar/interdisciplinar, a criticar y clarificar un presente polémico. Siobhan F. Guerrero nos propone que existen ciertas disciplinas gozne o umbrales en las que confluyen saberes y prácticas de otras heterogéneas disciplinas más internas o externas a lo 
típicamente biológico, y en las que se negocian y estabilizan las mediaciones entre éstas. Toma como ejemplo a la paleoantropología y a la bioarqueología, en las cuales confluyen saberes provenientes de las ciencias naturales, sociales y humanas. Nos propone la noción de arquitecturas disciplinares para analizar cómo en estos espacios heterogéneos se fraguan realidades (ontologías) de mediación que resultan cruciales para la comprensión de cómo las ciencias invaden, colonizan y asedian las fronteras de lo humano y de la subjetividad individual y colectiva.

En su contribución a este número Julio Muñoz Rubio revisita la polémica sobre los logros y la pretensiones explicativas de la psicología evolutiva en la versión de Tooby y Cosmides, apuntalado en una normativa crítica de lo que habría que esperar de una actividad genuinamente interdisciplinar, Muñoz propone que estos psicólogos combinan ineficazmente los recursos de otras ramas de la biología para dar cuenta evolutivamente de las proclividades psicológicas de Homo sapiens, sin conseguir la diana de explicaciones genuinas al "al no aplicar una concepción relacional y en cambio mantener una concepción esencialista [...]. Con ello su pretendida interdisciplina se pierde en favor de otra redisciplinarización, reduccionista e ideológica".

Sandra Caponi, en su artículo "La psiquiatrización de la vida cotidiana: el DSM y sus dificultades", nos introduce críticamente a las turbulencias ocasionadas en el medio psiquiátrico por las estrategias calificadoras y normativas introducidas por la quinta edición del Manual de Diagnóstico y Estadística de Enfermedades Mentales (DSM-5). Tomando como base de partida algunas críticas previas a los efectos nocivos de la construcción psiquiátrica de entidades patológicas de base causal y fisiológica inestable o inexistente de los DSM, Caponi añade otra serie de consideraciones que señalan lo descontrolada y peligrosa que parece ser la deriva sobre-clasificatoria y sobre-medicalizante actual y propone que se haga un alto en el camino y se reencamine la comprensión de las entidades psiquiátricas hacia posiciones menos simplistas y reduccionistas y más capaces de combinar visiones disciplinares en administración humana de la complejidad y sutileza de las subjetividades y psiques.

El trabajo colectivo de Florencia Arancibia, Ignacio Bocles, Alicia Massarini y Damián Verzeñassi se ocupa de ese espacio conflictivo de la gestión ambiental entre los designios de las políticas tecnocientíficas mercantiles, más o menos ajustadas a los saberes y valores de cierta investigación académica conservadora, por un lado, y los movimientos de resistencia y contrapropuesta política de las comunidades afectadas por las intervenciones en cuestión, sobre todo ambientales y de salud. Al explorar el caso de la introducción de cultivos de OGM en Argentina alentada por políticas gubernamentales y posiciones tecnocráticas de los investigadores, y la pobre consideración que se dio a los riesgos y preocupaciones genuinas de los grupos directamente afectados, puestos irresponsablemente en peligro sanitario, este trabajo describe cómo eso generó una serie de actos y reacciones creativas (articuladoras de futuro) como la creación del "Grupo de Epidemiología de la Ciencia Digna, que buscó desarrollar nuevas estrategias de investigación-acción para coproducir conocimiento entre científicos y comunidades, intentando superar las limitaciones" y solventar las diferencias.

La siguiente contribución del volumen, a cargo de Lev Jardón y Alonso Gutiérrez, se ocupa de preguntarse por las transiciones histórico-biológicas entre la naturaleza y la cultura en la construcción de la sociabilidad, en especial de la humana. Lo hace criticando las teorías recientes de la evolución cultural que se basan en la construcción de nicho, que tanto han sido discutidas en años recientes. El ejemplo de la domesticación de plantas y animales, y la complejidad de su historia y su inserción en la vida social y económica, sirve a estos autores para plantear la insuficiencia del abordaje teórico anglosajón en su versión actual, y la necesidad de enriquecer cualitativamente las capacidades de nuestro análisis con teorías más robustas, marxistas, de la historia y la sociedad, con el fin de comprender la verdadera sociabilidad en toda su profusión.

Esta sección cierra con el trabajo de Constanza Rendón y Gabriela Klier, quienes examinan textos representativos de algunas áreas de la biología (biología molecular, fisiología, biología de la conservación) para señalar la diversidad de nociones que existen en dicha literatura acerca del valor de lo vivo. En su examen las autoras distinguen entre valor productivo (organismos como herramientas), 
valor gnoseológico y valor intrínseco, este último concepto usado únicamente en biología de la conservación.

"Aproximaciones históricas a las ciencias de la vida" es el nombre de la séptima y última sección de este volumen. En ella los autores acuden a información factual y bibliográfica de casos centrados en el pensamiento biológico y alguno de sus aspectos social y culturalmente relevantes. Ricardo Noguera, Juan Manuel Rodríguez Caso y Rodrigo Bustillo utilizan el espacio de su trabajo para revisitar el problema del materialismo y antidualismo de los philosophes ilustrados franceses y su efecto en la concepción de la naturaleza y de la ciencia en Jean Baptiste Lamarck. La relación entre una posición metafísica, materialista y "reduccionista" y una práctica de la historia natural con leyes inmanentes a la materia viviente y sus telos autónomos es explorada, haciendo ver cómo todo está articulado, la concepción monista materialista determina en medida importante el método y el tipo de narrativa explicativa que de él se deriva. En sintonía con este trabajo está el que dedica Violeta Aréchiga a la concepción de lo vivo de (y del alma) en Schelling. El intento de la autora es por ubicar el pensamiento de este autor en el contexto de los debates historiográficos en torno a los modos y versiones del vitalismo del siglo XVIII y XIX. Aréchiga hace un análisis ceñido de los aspectos relevantes de la concepción de la vida de Schelling, y sus imbricaciones con otras de sus ideas, para concluir que su posicionamiento vitalista, aunque era anacrónico en apariencia para su época, es perfectamente inteligible y coherente con su proyecto filosófico y frente a los reduccionismos que aspiraba a limitar.

"El tema de la evolución biológica en los libros de texto de la escuela socialista en México (19301940)" es el título del penúltimo artículo de esta colección. Las autoras, Alicia Villela, Ana Barahona y Erica Torrens, nos hacen en él una exposición iluminadora de las situaciones culturales y políticas que llevaron a los gobiernos mexicanos de la posrevolución a manejar la enseñanza de la evolución como una herramienta de civilización y de pedagogía modernizadora que combatiera la superstición y la ignorancia no sólo de la historia de la vida en la Tierra sino sobre todo del lugar del ser humano en la naturaleza. Ello, obviamente, no sin grandes conflictos y controversias como los que suelen venir asociados a la propagación del darwinismo en contextos donde la religión es preponderante.

En el artículo final, Carlos López Beltrán explora diacrónica y sincrónicamente lo que él llama los "escenarios de la patologización racial" que se han dado en México con base en teorías científicas, racialistas. Con el fin de explicar el más reciente episodio de dicha patologización en esta época postgenómica, López Beltrán hace un recorrido histórico-analítico de las condiciones teóricas y culturales en las que se fueron dando los episodios previos, para mostrar que hay recurrencias y líneas de conexión entre todos ellos. De manera prominente la focalización de la mirada científica en el objeto político, cultural, y también científico (bioantropológico) del Mestizo Mexicano. "La idea tradicional de que los grupos mestizos de estas regiones heredaron fragilidades corporales y mentales de sus ancestros amerindios, que ha tenido versiones previas en escenarios teóricos cambiantes, se ha vuelto a articular, esta vez afincada en 'variantes genéticas amerindias' que supuestamente predisponen a enfermedades metabólicas a sus portadores, y que de ese modo explican las epidemias en curso", argumenta el autor.

Esta colección de artículos muestra, sin lugar a dudas, la vitalidad, hondura y compromiso que ha alcanzado en años recientes la comunidad de filósofos y otros estudiosos analíticos, empíricos y teóricos de las ciencias biológicas, antropológicas y biomédicas, en nuestro espacio cultural y político hispanoamericano. Las reuniones de AIFIBI (la próxima de las cuales tendrá lugar en Colombia, en 2018) han resultado ser un magnífico espacio de confluencia, interacción, diálogo crítico y forja de vínculos y de comunidad. En nuestra región, los filósofos de la biología se están haciendo presentes cada vez más para realizar la indispensable tarea de acompañar a las tecnociencias biológicas, bioantropológicas y biomédicas en su trayectoria crecientemente relevante, prometedora, al igual que riesgosa, siempre en busca de optimización. 